\title{
On the Inclination of the horizontal wires of a Transit Circle.
}

In deducing the zenith-distance of an object bisected at one side of the center of the field of view a correction for the inclination of the horizontal wire is always applied, when sensible. So far as I am aware this inclination, in the case of meridian instruments, is always deduced from circle readings corresponding to two or more bisections of a star at given instants of time during its transit across the field of view. I would suggest the following simple and accurate method by means of which this constant can be easily found at all times.

The telescope is pointed to a (say the south) collimator, and the horizontal wire of this collimator made

Ann Arbor, Mich., I 885 March 5. parallel to the horizontal wire of the telescope. The horizontal wire of the north collimator is then made parallel to the image of the south collimator wire. The telescope is then turned to the north collimator and the inclination of the telescope wire to the image of the collimator wire deduced from the circle readings corresponding to bisections made at, or near, the two extremities of the horizontal wire. One half of the difference of the circle readings divided by the angular distance between the points of bisection will evidently give the tangent of the angle which the horizontal wire makes with the axis of rotation.

\section{F. M. Schaeberle.}

\section{Dr. Gould's star in Sculptor.}

The very interesting star with large proper motion discovered by Dr. Gould (A. N. 2656) was observed in the Washington Transit Zones, 1846 Sept. 16 , Zone 7 , No. 60,

$$
\text { (1 } \left.85^{\circ}\right) \quad 23^{\mathrm{h}} 56^{\mathrm{m}} 31^{\mathrm{s}} \cdot 37-38^{\circ} 5^{\prime} 3^{2 .} \cdot 7
$$

Reducing this to 1875 , we have

$$
\text { (I } 875) \quad 23^{\mathrm{h}} 57^{\mathrm{m}} 4^{8} 8^{\mathrm{s}} .49-37^{\circ} 57^{\prime} \text { I I."4 }
$$

and assigning it the weight $1 / 2$, and to Dr. Gould's places weights corresponding to the number of observations in each year, I get the place and proper motion, with the probable errors appended.

$$
\begin{aligned}
a & =23^{\mathrm{h}} 58^{\mathrm{m}} \text { 1.90 } \\
\delta & =-37^{\circ} 58^{\circ} 19^{\prime \prime 1} 7 \pm 0.02 \\
\mu \text { in } a & =\quad+0.4757 \pm 0.0023 \\
\mu \text { in } \delta & =\quad-2.3890 \pm 0.0301
\end{aligned}
$$

which satisfy the observed places as follows $(\mathrm{O}-\mathrm{C})$ :

\begin{tabular}{c|c|c|c}
\hline Epoch & $W \mathrm{t}$ & $\Delta \alpha$ & $\Delta \delta$ \\
\hline $\mathrm{I} 846.7$ & $1 / 2$ & +0.05 & +0.2 \\
$\mathrm{I} 872.9$ & 2 & +0.02 & +0.2 \\
$\mathrm{I} 875.9$ & $\mathrm{I}$ & -0.13 & +0.6 \\
$\mathrm{I} 880.8$ & 3 & -0.03 & -1.0 \\
$\mathrm{I} 884.8$ & 4 & +0.04 & +0.5
\end{tabular}

The proper motions above given are very slightly smaller both in RA. and Decl. than Dr. Gould finds from the Cordoba observations alone, and correspond to a motion in a century of $6 \mathrm{I}^{\prime \prime} 44$ arc of a great circle.

A comparison of the adjacent stars in the Wash. Zone with their places in Gould's Zone Catalogue shows a well defined systematic difference +0.06 and -2." 5 for that region. If we apply these corrections to the Wash. place to render it homogeneous with the rest, the above coordinates and proper motions assume in the solution the following modified values which are perhaps to be preferred:

$$
\begin{aligned}
& \text { I } 875 \\
& \alpha=23^{\mathrm{h}} 5^{8^{\mathrm{m}}} \mathbf{1} \cdot 90 \quad \delta=-37^{\circ} 5^{\mathrm{s}} 19^{\prime \prime} 49 \\
& \left.\begin{array}{l}
\mu \text { in RA. +o.4744 } \\
\mu \text { in Decl. }-2.3338
\end{array}\right\}=607.56 \text { in a century }
\end{aligned}
$$

with insignificant differences in the residual and probable errors from those above given.

Cambridge, U. S. A., I 885 April I 2.

\section{S. C. Chandler jr.}

Zusatz. Prof. Holden macht in einer Zuschrift vom 13. April ebenfalls auf die ältere Beobachtung in Washington aufmerksam. $K r$.

\section{Berichtigung zu A. N. 2645, den Stern Lacaille 784 betreffend.}

Im Capcatalog für 1880 sind bei Nr. 1025 die Praecession in AR. und die beiden Saecular-Aenderungen unrichtig angegeben und der Reihe nach zu lesen +2.5974, - 0.0013 , +0."236. Nach den Beobachtungen von Gould (Zonencatalog $2^{\mathrm{h}} 760$, und Jahrescatalog 1873 Nr. 225) ist es auch sehr wahrscheinlich, dass die AR. des Capcatalogs mit der unrichtigen Praecession auf die Epoche i 880 reducirt und (unter der Voraussetzung, dass alle drei Beobachtungen dem Jahre 1878 angehören) um +o.22 zu corrigiren, also $2^{\mathrm{h}} 28^{\mathrm{m}} 37^{\mathrm{s}} \cdot 50 \mathrm{zu}$ lesen ist.

Unter dieser Annahme erhält man 2 . B. ohne Rücksicht auf constante Unterschiede der Cataloge und auf Eigenbewegung Stone (1878) - Moesta (1855) $\Delta \alpha=+0 .{ }^{5} 3$, $\Delta \delta=+\mathrm{r} .4$, womit auch die andern, von Herrn Holden S. 75 des Bandes citirten Quellen genügend stimmen. Der Stern gehört also nicht zu den stark bewegten. 